\title{
Comparative Study of Salivary and Serum Levels of Vitamin D in Patients with a History of High Blood Pressure and Healthy People
}

\author{
Hamidreza Abdolsamadi ${ }^{1}$, Mohammad vahedi ${ }^{2}$, Farnaz Fariba ${ }^{3}$, Alireza Soltanian ${ }^{4}$, Meghdad Zakavati Avval $^{5}$, \\ $\&$ Ali Hosseini ${ }^{5}$ \\ ${ }^{1}$ Dental Research Center, Department of Oral Medicine, Dental School, Hamadan University of Medical Sciences, \\ Hamadan, Iran \\ ${ }^{2}$ Dental Research Center, Department of Oral \& Maxillofacial Medicine, Dental School, Hamadan University of \\ medical sciences, Hamadan, Iran \\ ${ }^{3}$ Department of Cardiology, School of Medicine, Hamadan University of Medical Sciences, Hamadan, Iran \\ ${ }^{4}$ Department of Biostatistics, school of public Health, Hamadan, Iran \\ ${ }^{5}$ Department of Oral \& Maxillofacial Medicine, Dental School, Hamadan University of Medical Sciences, \\ Hamadan, Iran \\ Correspondence: Meghdad Zakavati Avval, Postgraduate of Oral Medicine, Department of Oral \& Maxillofacial \\ Medicine, Dental School, Hamadan University of Medical Sciences, Hamadan, Iran. E-mail: zakavati_dds@yahoo.com
}

Received: July 9, 2017

doi:10.5539/jmbr.v8n1p101
Accepted: July 21, 2018

Online Published: July 24, 2018

URL: https://doi.org/10.5539/jmbr.v8n1p101

\begin{abstract}
Introduction: Vitamin D deficiency is a major public health problem. Low vitamin D levels associated with adverse health consequences such as musculoskeletal health, cognitive decline and progression of cancer and death The lack of vitamin D associated with major risk factors for cardiovascular disease (CVD) includes hypertension is considered. The ability to assess the general health, disease and treatment outcomes through saliva as a noninvasive, inexpensive and simple method of interest is located. The aim of this study was a comparative study of salivary and serum levels of vitamin D3 in patients with a history of developing high blood pressure and a healthy person.
\end{abstract}

Methods: This study was a case - control survey, in which 40 patients with high blood pressure were examined. The control group including 40 healthy subjects. Both groups were matched in terms of age and gender. After collecting samples of serum and saliva, the amount of vitamin D level samples were measured using ELISA method by electrochemiluminescence (ELC), and then analyzed the results using software SPSS 16 and statistical test including Chi Square Test, Independent-Samples, linear regression model, the Mann-Whitney Test and Spearman correlation coefficient.

Results: There was no significant difference in the mean serum levels of vitamin D among patients and healthy subjects $(\mathrm{p}=0.588)$. In addition, there was no significant difference in the mean salivary levels of vitamin $\mathrm{D}$ between patients and healthy subjects $(\mathrm{p}=0.833)$. There was no significant relationship between salivary and serum level of vitamin $\mathrm{D}$ in healthy individuals $(\mathrm{p}=0.095)$. As well as there was no significant correlation between salivary and serum level of vitamin $\mathrm{D}$ in patients $(\mathrm{p}=0.5)$.

Conclusions: This study showed that vitamin D is a measurable marker in saliva, but its analysis in saliva, may not be a reliable tool for determining the vitamin $\mathrm{D}$ levels.

Keywords: hypertension; vitamin D; saliva

\section{Introduction}

Vitamin D deficiency is a public health problem that affects 58-33 percent of the population of the United States (Deng et al., 2013; Hossein-nezhad \& Holick, 2013). Low levels of vitamin D status are associated with adverse health consequences such as musculoskeletal health (Holick 2007; Souberbielle et al., 2010), cognitive decline (van der Schaft et al., 2013) and cancer progression and death (Freedman, Looker, Chang, \& Graubard, 2007). More recently, the relationship between vitamin $\mathrm{D}$ deficiencies are the major risk factors for cardiovascular disease (CVD) including hypertension (Motiwala \& Wang, 2012; Souberbielle et al., 2010; Vimaleswaran et al., 2014). 
Vitamin D by acting on the renin-angiotensin system plays an important role in controlling blood pressure. According to the results of the studies, there is an inverse relationship between vitamin D deficiency and increased risk of high blood pressure. The results of the studies have shown that with the placement of people with high blood pressure exposed to UVB rays of sunlight, vitamin d levels are increased; reduced systolic and diastolic blood pressure, as well as the results of another study showed that adding vitamin D food leads to lower diastolic blood pressure in patients with high blood pressure. In general, the usual diet containing insufficient amounts of vitamin D, and without supplements, Sunlight to reach sufficient levels of vitamin D for humans is necessary. The synthesis of vitamin D in the skin depends on several factors such as geographical location, altitude, latitude, season, day length, color, age and obesity (Naesgaard et al., 2012). Lack of vitamin D from different directions, causing cardiovascular disease that includes vascular smooth cell proliferation, hypertrophy of myocardial cells, vascular calcification, the renin-angiotensin system disorders, pancreatic beta cells disorders and insulin resistance that they have playing role in the blood pressure disorders (Hosseinpanah et al., 2011). Saliva is a complex combination of water and organic and inorganic components that are the major and minor salivary glands. The majority of compounds can be produced locally within the glands and other parts of the systemic circulation moves (Glick, 2015 ). The ability of the public health assessment to determine the onset of the disease and treatment outcomes through saliva as a non-invasive method, the most important goal in the progress towards the use of salivary markers can be taken in to account. Very good reasons for the use of saliva as a diagnostic fluid for evaluation of health and disease. Interest in faster and less invasive diagnostic tests has grown in the past decade, that extensive research has resulted in saliva as liquid bio clinical diagnosis (Sun \& Reichenberger, 2014). So the diagnosis of disease based on collecting the saliva is very more accessible, more accurate and cheaper would be superior to the other methods are the least risk for the patient and can also be a cost-effective and non-invasive methods in large populations provide screening (Lawrence, 2002). The aim of this study was to compare the salivary and serum levels of vitamin D3 in the case Group (includes patients with a history of hypertension, they visit) versus healthy subjects (without any history of heart and vascular disease and without any known systemic disease requires long-term treatment).

\section{Methods}

This is a case-control study. The statistical community selected including 40 patients referred to clinic of farshchian heart hospital of Hamadan from September 2016 to March 2017, who were suffering from high blood pressure. The control group comprised 40 healthy subjects that matched in terms of age and sex were observed Inclusion criteria to select patients, patients with a history of hypertension greater than 140/90 $\mathrm{mmHg}$ in patients greater than 30 years. Inclusion criteria (including all subjects, including control and monitoring) are as follows: Everyone is at least 30 years of age. There is no chronic kidney disease (men $\mathrm{Cr}<1.8$ in women $\mathrm{Cr}<1.5$ ). Calcium levels were in the normal range. During the past four months had not received any calcium supplements. None of these patients had autoimmune inflammatory disease such as infection and active disease. Also not treated with corticosteroids. Eventually to participate in the study were completely satisfied. Exclusion criteria included age less than 30 years, taking vitamin D and calcium has over 4 months before the study. Creatinine level higher than 1.8 for men and 1.5 for women. Patients with chronic inflammatory diseases and infection in patients treated with systemic corticosteroids. Levels less than $20 \mathrm{ng} / \mathrm{mL}(50 \mathrm{nmol} / \mathrm{L})$ 25-hydroxyvitamin D3 as shortages; Levels of 29-21 ng / $\mathrm{ml}(52-72 \mathrm{nmol} / \mathrm{L})$ as insufficient, and the level greater than $30 \mathrm{ng} / \mathrm{ml}$ is considered to be a sufficient amount of vitamin D (Holick, 2009). According to JNC 8 normal blood pressure is less than 120/80 $\mathrm{mmHg}$ blood pressure (pre-hypertension blood pressure; Systolic 120-139 mmHg and diastolic pressure between $89-80 \mathrm{mmHg}$. stage 1 hypertension, systolic 140-159 $\mathrm{mmHg}$ and diastolic blood pressure 90-99 $\mathrm{mmHg}$. finally, stage 2 hypertension, systolic blood pressure over $160 \mathrm{mmHg}$ and diastolic pressure over $100 \mathrm{mmHg}$ (Paul et al., 2014). Blood samples taken from the brachial vein with $5 \mathrm{ml}$ syringe. Saliva sampling of all the participants in the study using the method of "navazesh" preparation (Navazesh \& Kumar, 2008). Unstimulated saliva samples was taken between 8-11 am and all the volunteers in the study were asked for 90 minutes before collecting samples avoid eating, drinking and brushing. Then people sitting while the head is bent slightly forward, For 5 minute's saliva poured into a graduated tube. Serum and saliva samples stored in the icebox $4{ }^{\circ} \mathrm{C}$, and immediately Within 20 minutes sent to a laboratory. Where they were stored in a freezer at $-30^{\circ} \mathrm{C}$. To describe the data collected from the indicators such as average, standard deviation, and charts used to determine the relationship between demographic variables and Regression models to examine the relationship between levels of vitamin D in serum and saliva and blood pressure used. The significance level of less than 0.05 , and for statistical analysis software SPSS 16 considered. 


\section{Findings}

There was no significant relationship between salivary and serum level of vitamin $\mathrm{D}$ in healthy individuals $(P=$ 0.095). As well as there was no significant correlation between salivary and serum level of vitamin $\mathrm{D}$ in patients $(P=0.5)$ (table 1). Considering that, healthy and patient groups in terms of age were the same, so in order to dampen the effect of the two-group comparison of regression model used. Serum levels of vitamin $D$ in healthy and patient groups show that there was no significant relationship between the two groups $(P=0.588)$ (table 2). Comparison of salivary levels of vitamin $\mathrm{D}$ in healthy and patient groups shows that there was no significant relationship between the two groups $(P=0.833)$. Two groups of healthy and sick in terms of gender distribution had no significant differences $(P=0.247)$ (table 3$)$. In this study, healthy and patient groups did not differ in terms of mean age $(P<0.001)$. However, the BMI is not a significant difference between healthy and sick people ( $P=$ $0.55)$ (table 4). There was no significant difference in the mean serum vitamin D levels among healthy men and women. $(P=0.627)$. There was no significant difference in the mean salivary levels of vitamin $\mathrm{D}$, between men and women $(P=0.537)$. There was no significant difference between the average serum levels of vitamin $\mathrm{D}$ for healthy men and women $(P=0.537)$. There was no significant difference in the mean serum levels of vitamin $\mathrm{D}$, between male and female patients $(P=0.44)$ (table 5$)$. There was no significant in the mean salivary levels of vitamin $\mathrm{D}$ difference between male and female patients $(P=0.044)$. There was no significant relationship between the serum levels of vitamin $\mathrm{D}$ and age in healthy individuals $(P=0.108)$. There was no significant relationship between salivary levels of vitamin $\mathrm{D}$ and age in healthy individuals $(P=0.13)$. There was no significant relationship between serum vitamin D levels, and the age of the people. $(P=0.119)$. There was no significant relationship between the salivary levels of vitamin $\mathrm{D}$ and the patient's age in people $(P=0.903)$ (table 6). There was no significant relationship between serum vitamin $\mathrm{D}$ levels and BMI in normal individuals $(P=0.987)$. There was no significant relationship between serum vitamin $\mathrm{D}$ levels and BMI in patients $(P=0.718)$. There was no significant relationship between the salivary levels of vitamin $\mathrm{D}$ and BMI in normal individuals $(P=0.462)$. There was no significant relationship among the salivary levels of vitamin D and BMI in patients $(P=0.798)$ (table 7). There was no significant difference in the Serum levels of vitamin D among smokers and non-smokers healthy group $(P=0.409)$. There was no significant difference in Salivary levels of vitamin $\mathrm{D}$ among smokers and nonsmokers healthy group $(P=0.537)$. There was no significant difference in Serum levels of vitamin $\mathrm{D}$ among smokers and non-smokers patient group $(P=0.959)$. There was no significant difference in Serum vitamin D levels between smokers and nonsmokers patient group $(P=0.108)$ (table 8$)$. There was no significant relationship between the serum level of calcium (Ca) with serum levels of vitamin $\mathrm{D}$ in the healthy group $(P=0.533)$. There was no significant relationship between the serum level of calcium (Ca) with serum levels of vitamin $\mathrm{D}$ in the patient group $(P=0.849)$ (table 9$)$.

Table 1. Comparison of salivary and serum levels of vitamin D (VD3) in healthy and patient groups

\begin{tabular}{|c|c|c|c|c|}
\hline Group & Healthy & & Patient & \\
\hline correlation coefficient & $\begin{array}{l}\text { Spearman correlation } \\
\text { coefficient }\end{array}$ & $\begin{array}{c}P \text { - } \\
\text { value }\end{array}$ & $\begin{array}{l}\text { Spearman correlation } \\
\text { coefficient }\end{array}$ & $\begin{array}{c}P- \\
\text { value }\end{array}$ \\
\hline $\begin{array}{c}\text { Serum levels of VD3 with Salivary levels of } \\
\text { VD3 }\end{array}$ & 264.-0 & 095.0 & 04.-0 & 5.0 \\
\hline
\end{tabular}

Table 2. Compares the average level of vitamin D (VD3) in both saliva and serum of healthy and patient group

\begin{tabular}{cccc}
\hline group & Healthy mean \pm sd & Patient mean \pm sd & Linear regression model \\
\hline Salivary VD3 level & $86.52 \pm 49.54$ & $77.85 \pm 19.13$ & Std.error $=10.768$ \\
& & & $P^{*}=0.833$ \\
Serum VD3 level & $88.85 \pm 98.73$ & $80.7 \pm 67.48$ & $\mathrm{~B}=-14.381$ \\
& & & Std.error $=26.452$ \\
& & $P^{*}=0.588$
\end{tabular}

* - significant levels of salivary and serum samples for comparison with the implementation of the (adjust) age was conducted. 
Table 3. Comparison between healthy and patient groups in terms of gender

\begin{tabular}{cccc}
\hline Sex & Healthy & Patient & Chi-Square Tests \\
\hline Female & $30(73.2 \%)$ & $27(61.4 \%)$ & $\mathrm{X}^{2}=1.339 \mathrm{a}$ \\
& & & $\mathrm{df}=1$ \\
Male & $11(26.8 \%)$ & $17(38.6 \%)$ & $P=0.247$ \\
\hline
\end{tabular}

Table 4. Comparison of two groups of healthy and sick in terms of age and BMI

\begin{tabular}{cccc}
\hline group & Healthy & Patient & Independent Samples Test \\
\hline \multirow{2}{*}{ Age (year) } & $43.78 \pm 9.53$ & $60.84 \pm 9.52$ & $\mathrm{~T}=-8.254$ \\
& & $\mathrm{df}=83$ \\
& & $P<0.001$ \\
\multirow{2}{*}{ BMI } & $26.12 \pm 4.53$ & $26.63 \pm 4.53$ & $\mathrm{~T}=-0.6$ \\
& & $\mathrm{df}=83$ \\
& & $P<0.55$ \\
\hline
\end{tabular}

Table 5. Comparison of salivary and serum level of vitamin D in men and women in each of the two groups of healthy and sick

\begin{tabular}{ccccc}
\hline \multirow{2}{*}{ Group } & & \multicolumn{3}{c}{ Sex } \\
\cline { 3 - 5 } & & man & woman \\
mean \pm sd & mean \pm sd & Mann-Whitney Test \\
\hline Healthy & Salivary level & $73.98 \pm 30.62$ & $91.12 \pm 54.6$ & $\begin{array}{c}\text { Mann-Whitney U }=0.144 \\
\end{array}$ \\
& & & & $P=0.537$ \\
& Serum level & $93.39 \pm 112.78$ & $87.18 \pm 95.13$ & Mann-Whitney U $=148.5$ \\
& & & $P=0.627$ \\
& & & & Mann-Whitney U $=146$ \\
& Salivary level & $70.41 \pm 16.85$ & $82.53 \pm 19.28$ & $P=0.044$ \\
& & & & Mann-Whitney U $=197.5$ \\
& Serum level & $57.81 \pm 69.69$ & $73.57 \pm 87.65$ & $P=0.44$ \\
\hline
\end{tabular}

Table 6. The relationship between salivary and serum vitamin D levels with age

\begin{tabular}{cccc}
\hline Group & Vitamin D levels & Spearman correlation coefficient & p- value \\
\hline \multirow{2}{*}{ Healthy } & Serum levels with age & 0.255 & 0.108 \\
& Salivary levels with age & -0.241 & 0.13 \\
\multirow{2}{*}{ Sick } & Serum levels with age & 0.239 & 0.119 \\
& Salivary levels with age & -0.019 & 0.903 \\
\hline
\end{tabular}

Table 7. The relationship between salivary and serum vitamin D levels with BMI

\begin{tabular}{ccccc}
\hline Group & \multicolumn{2}{c}{ sick } & \multicolumn{2}{c}{ Healthy } \\
\hline correlation coefficient & Spearman correlation coefficient & $P$-value & Spearman correlation coefficient & $P$-value \\
Serum levels with BMI & -0.058 & 0.718 & -0.004 & 0.987 \\
Salivary levels with BMI & -0.041 & 0.798 & 0.114 & 0.462 \\
\hline
\end{tabular}


Table 8. Comparison of salivary and serum vitamin D levels in smokers in each of the groups of healthy and sick

\begin{tabular}{|c|c|c|c|c|}
\hline Group & Vitamin D levels & $\begin{array}{l}\text { Smoker } \\
\text { mean } \pm \text { sd }\end{array}$ & $\begin{array}{c}\text { Non-smoker } \\
\text { mean } \pm \text { sd }\end{array}$ & Mann-Whitney Test \\
\hline \multirow{2}{*}{ Healthy } & Serum levels & $121.32 \pm 128.05$ & $76.94 \pm 85.12$ & $\begin{array}{c}\text { Mann-Whitney } \mathrm{U}=137 \\
\qquad P=0.409\end{array}$ \\
\hline & Salivary levels & $88.6 \pm 41.15$ & $85.76 \pm 52.9$ & $\begin{array}{c}\text { Mann-Whitney } \mathrm{U}=144 \\
P=0.537\end{array}$ \\
\hline \multirow{2}{*}{ Sick } & Serum levels & $63.64 \pm 78.77$ & $69.1 \pm 82.72$ & $\begin{array}{c}\text { Mann-Whitney } \mathrm{U}=199.5 \\
P=0.959\end{array}$ \\
\hline & Salivary levels & $69.25 \pm 18.45$ & $81.46 \pm 18.52$ & $\begin{array}{c}\text { Mann-Whitney } \mathrm{U}=139 \\
\qquad P=0.108\end{array}$ \\
\hline
\end{tabular}

Table 9. The relationship between serum levels of calcium $(\mathrm{Ca})$ with vitamin D serum levels in healthy and sick

\begin{tabular}{ccccc}
\hline Group & Healthy & \multicolumn{2}{c}{ Sick } \\
\hline correlation coefficient & Spearman correlation coefficient & $P$-value & Spearman correlation coefficient & $P$-value \\
Serum Ca with serum vitamin D & -0.101 & 0.533 & 0.03 & 0.849 \\
\hline
\end{tabular}

\section{Conclusion}

The findings of this study between serum levels of vitamin D and salivary levels of vitamin D in people with high blood pressure compared to healthy subjects did not find a significant relationship. The study of RCT that Pilz and colleagues did in 1981 showed that in patients who are suffering from high blood pressure and low levels of 25 $(\mathrm{OH}) \mathrm{D}$, vitamin D supplementation on blood pressure and several other risk factors, there was no significant effect. Of course, a significant increase in the plasma triglyceride group there was vitamin D (Pilz et al., 2015). Higashi and colleagues (2008) stated that a reliable comparison between concentrations of $25(\mathrm{OH}) \mathrm{D}$ serum and saliva. As a result, the proposed method for the evaluation of $25(\mathrm{OH}) \mathrm{D}$ saliva non-invasive alternative for measuring serum vitamin D status provides assessment (Higashi, Shibayama, Fuji, \& Shimada, 2008). It seems, this discrepancy results due to differences in the method of measurement of vitamin D serum and saliva. (Skaaby, 2015). Park and colleagues (2015) in his study of $535 \mathrm{n}$ Korean people over 60 years showed that genetic changes in CYP1A1 and CYP1B1 and serum level of $25(\mathrm{OH})$ D synergy effects on blood pressure, especially in people who are currently under the treatment of high blood pressure (Park et al., 2015). This difference may seem due to the difference in the age range chosen in the statistical society that we studied over the age of 30 years, or the method of measuring vitamin D, and perhaps the difference in geographical location. Wang et al (2013) in their prospective cohort study based on the evidence suggested that between $25(\mathrm{OH}) \mathrm{D}$ plasma and the risk of high blood pressure, there is an inverse relationship (Wang et al., 2013). This difference in results can be caused by a difference in the method of measurement of plasma vitamin D, geographic location or a different way of life subjects. Another study by Karimi Hassan Abad and his colleagues in 2014 aimed at investigating the prevalence of vitamin D deficiency and its association with the obesity index (BMI) and abdominal obesity in adolescent girls aged 14 to 17 years. The concentration of vitamin D was measured by ELISA method (Vitamin D Kit ERUIMMUN Germany). It was reported that vitamin D had no significant correlation with waist circumference (central obesity index) (Karimi- Hasanabad, Rafraf, \& Asghari-Jafarabadi, 2014), but in our study, there was no significant relationship between serum salivation levels of vitamin D and BMI in healthy subjects. This difference could be due to differences in the age group of the target group or the choice of measuring kit by two studies.

\section{Conclusion}

The results of this study showed that, there was no significant relationship between high blood pressure and salivary and serum vitamin D level. Vitamin D is measurable in saliva But given the absence of significant relation between serum and saliva, saliva analysis of vitamin D, May not be a reliable tool for determining the vitamin D levels. 


\section{Suggestions}

Recommended that research in the future by employing more advanced laboratory techniques and monitoring, including the use of modern laboratory methods based on Nano technology as well as the salivary and vitamin D Kit build tools with more sensitivity to salivary samples collected.

\section{References}

Deng, X., Song, Y., Manson, J. E., Signorello, L. B., Zhang, S. M., Shrubsole, M. J., . . Dai, Q. (2013). Magnesium, vitamin D status and mortality: results from US National Health and Nutrition Examination Survey (NHANES) 2001 to 2006 and NHANES III. BMC Med, 11(1), 187. https://doi.org/10.1186/1741-7015-11-187

Freedman, D. M., Looker, A. C., Chang, S. C., \& Graubard, B. I. (2007). Prospective study of serum vitamin D and cancer mortality in the United States. J Natl Cancer Inst, 99(21), 1594-1602. https://doi.org/10.1093/ jnci/djm204

Glick, M. (2015). Burket's Oral Medicine (M. Glick Ed. 12 ed.). India Jaypee Brothers Medical Publishers.

Higashi, T., Shibayama, Y., Fuji, M., \& Shimada, K. (2008). Liquid chromatography-tandem mass spectrometric method for the determination of salivary 25-hydroxyvitamin D3: a noninvasive tool for the assessment of vitamin D status. Analytical and Bioanalytical Chemistry, 391(1), 229-238. https://doi.org/10.1007/s00216007-1780-3

Holick , M. F. (2007). Vitamin D Deficiency. New England Journal of Medicine, 357(3), 266-281. https://doi.org/10.1056/NEJMra070553

Holick, M. F. (2009). Vitamin D status: Measurement, interpretation and clinical application. Annals of epidemiology, 19(2), 73-78. https://doi.org/10.1016/j.annepidem.2007.12.001

Hossein-nezhad, A., \& Holick, M. F. (2013). Vitamin D for health: a global perspective. Mayo Clin Proc, 88(7), 720-755. https://doi.org/10.1016/j.mayocp.2013.05.011

Hosseinpanah, F., Yarjanli, M., Sheikholeslami, F., Heibatollahi, M., Eskandary, P. S., \& Azizi, F. (2011). Associations between vitamin D and cardiovascular outcomes; Tehran Lipid and Glucose Study. Atherosclerosis, 218(1), 238-242. http://dx.doi.org/10.1016/j.atherosclerosis.2011.05.016

Karimi- Hasanabad, S., Rafraf, M., \& Asghari-Jafarabadi, M. (2014). Prevalence of vitamin D deficiency and its relationship with body mass index and waist circumference in female Adolescents 14-17 years, Boukan. Iranian Journal of Diabetes and Lipid Disorders, 14(1), 55-62.

Lawrence, H. P. (2002). Salivary markers of systemic disease: noninvasive diagnosis of disease and monitoring of general health. $J$ Can Dent Assoc, 68(3), 170-174.

Motiwala, S. R., \& Wang, T. J. (2012). Vitamin D and cardiovascular risk. Curr Hypertens Rep, 14(3), 209-218. https://doi.org/10.1007/s11906-012-0262-y

Naesgaard, P. A., León De La Fuente, R. A., Nilsen, S. T., Woie, L., Aarsland, T., Brede, C., . . Nilsen, D. W. T. (2012). Serum 25(OH)D Is a 2-Year Predictor of All-Cause Mortality, Cardiac Death and Sudden Cardiac Death in Chest Pain Patients from Northern Argentina. PLOS ONE, 7(9), e43228. https://doi.org/10.1371/ journal.pone. 0043228

Navazesh, M., \& Kumar, S. K. (2008). Measuring salivary flow: challenges and opportunities. J Am Dent Assoc, 139, Suppl(5), 35S-40S.

Park, H. Y., Kim, J. H., Bae, S., Choi, Y. Y., Park, J. Y., \& Hong, Y. C. (2015). Interaction effect of serum 25hydroxyvitamin D levels and CYP1A1, CYP1B1 polymorphisms on blood pressure in an elderly population. J Hypertens, 33(1), 69-76. https://doi.org/10.1097/HJH.0000000000000381

Paul, A. J., Barry, L. C., Cushman, W. C., Handler, J., LeFevre, M. L., MacKenzie, T. D., \& al, e. (2014). 2014 Evidence-Based Guideline for the Management of High Blood Pressure inAdults Report From the Panel Members Appointed to the Eighth Joint National Committee (JNC 8). JAMA, 311(5), 507-520.

Pilz, S., Gaksch, M., Kienreich, K., Grubler, M., Verheyen, N., Fahrleitner-Pammer, A., . . Tomaschitz, A. (2015). Effects of vitamin D on blood pressure and cardiovascular risk factors: a randomized controlled trial. Hypertension, 65(6), 1195-1201. https://doi.org/10.1161/hypertensionaha.115.05319

Skaaby, T. (2015). The relationship of vitamin D status to risk of cardiovascular disease and mortality. Dan Med $J, 62(2), 1-17$. 
Souberbielle, J. C., Body, J. J., Lappe, J. M., Plebani, M., Shoenfeld, Y., Wang, T. J., . . Zittermann, A. (2010). Vitamin D and musculoskeletal health, cardiovascular disease, autoimmunity and cancer: Recommendations for clinical practice. Autoimmun Rev, 9(11), 709-715. https://doi.org/10.1016/j.autrev.2010.06.009

Sun, F., \& Reichenberger, E. J. (2014). Saliva as a source of genomic DNA for genetic studies: review of current methods and applications. Oral Health Dent Manag, 13(2), 217-222.

van der Schaft, J., Koek, H. L., Dijkstra, E., Verhaar, H. J., van der Schouw, Y. T., \& Emmelot-Vonk, M. H. (2013). The association between vitamin D and cognition: a systematic review. Ageing Res Rev, 12(4), 10131023. https://doi.org/10.1016/j.arr.2013.05.004

Vimaleswaran, K. S., Cavadino, A., Berry, D. J., LifeLines Cohort Study, i., Jorde, R., Dieffenbach, A. K., . . Hypponen, E. (2014). Association of vitamin D status with arterial blood pressure and hypertension risk: a mendelian randomisation study. Lancet Diabetes Endocrinol, 2(9), 719-729. https://doi.org/10.1016/S22138587(14)70113-5

Wang, L., Ma, J., Manson, J. E., Buring, J. E., Gaziano, J. M., \& Sesso, H. D. (2013). A prospective study of plasma vitamin D metabolites, vitamin D receptor gene polymorphisms, and risk of hypertension in men. Eur J Nutr, 52(7), 1771-1779. https://doi.org/10.1007/s00394-012-0480-8

\section{Copyrights}

Copyright for this article is retained by the author(s), with first publication rights granted to the journal.

This is an open-access article distributed under the terms and conditions of the Creative Commons Attribution license (http://creativecommons.org/licenses/by/4.0/). 